\title{
PENGARUH DOSIS TABLET MIKORIZA TERHADAP PERTUMBUHAN TANAMAN MUDA MERANTI MERAH DARI BENIH DAN STEK DI HPH PT ITCIKU, BALIKPAPAN KALIMANTAN TIMUR
}

(Effect of Mycorhizal Tablet Dosage on the Growth Red Meranti of Young Plantation From Seeds and Cuttings at PT. ITCIKU Concession Holder, Balikpapan East Kalimantan)

\author{
Oleh/By : \\ R. Mulyana Omon \\ Balai Penelitian Teknologi Perbenihan Samboja
}

\begin{abstract}
A study on the effect of mycorrhizal tablet dosage on the growth of red meranti (Shorea johorensis Foxw. and Shorea leprosula Miq.) young plant from seeds and cuttings was conducted at PT. ITCIKU, Balikpapan East Kalimantan. The purpose of this research was to determine the optimal dosage of mycorrhizal tablet inoculum on the growth of two red meranti species from seeds and cuttings. Two species (S. johorensis Foxw. and S. leprosula Miq.), two seedling origin (seeds and cuttings) and two dosages inoculum of mycorrhizal tablets (one tablet and two tablets ) per seedling and without inoculation (control) were tested. Factorial completely randomized design with three replications was used for this study. Before planting in the field, each plant from seeds and cuttings were inoculated with mycorrhizal tablet during four months in nursery. Each treatment consisted of 15 plants were planted with $6 \mathrm{~m} \times 3 \mathrm{~m}$ spacing. The total number of plants observed was 540 plants. The results showed that different dosages, source of seedlings and their interactions did not show a significant different on the survival percentage. The survival percentage of S. leprosula was higher compared to S. johorensis, they were $81.11 \%$ and $57.24 \%$, respectively. The interaction between $\mathrm{S}$. Leprosula and seedling from cutting showed a significant different on height growth as much as $86.28 \mathrm{~cm}$ compared with other interaction treatments.
\end{abstract}

Key words : Red meranti, seed, cutting, mycorrhizal tablet Shorea johorensis Foxw. and Shorea leprosula Miq.

\begin{abstract}
ABSTRAK
Penelitian pengaruh tablet mikoriza terhadap pertumbuhan tanaman muda meranti merah (Shorea johorensis Fowx. dan Shorea leprosula Miq.) dari bibit yang berasal dari benih dan stek telah dilakukan di areal Hak Pengusahaan Hutan PT ITCIKU, Balikpapan Kalimantan Timur. Tujuan penelitian ini adalah untuk mengetahui dosis tablet mikoriza yang efektif terhadap pertumbuhan meranti merah dari bibit yang berasal dari benih dan stek. Dua jenis meranti merah (S. johorensis Foxw. dan S. leprosula Miq.), dua asal bibit (dari benih dan stek) dan dua dosis tablet mikoriza (satu tablet dan dua tablet mikoriza) serta tanpa diberi tablet mikoriza yang digunakan sebagai perlakuan. Rancangan percobaan yang digunakan adalah faktorial dalam pola acak lengkap yang diulang sebanyak tiga kali. Sebelum bibit ditanam dilakukan inokulasi dengan tablet mikoriza dan setelah empat bulan di persemaian kemudian ditanam di lapangan. Setiap perlakuan ditanam sebanyak 15 tanaman dengan jarak tanam $6 \mathrm{~m} \times 3 \mathrm{~m}$. Jumlah tanaman yang diamati sebanyak 540 tanaman. Hasil penelitian menunjukkan bahwa perlakuan dosis tablet mikoriza, macam bibit dan semua interaksi antara perlakuan tidak berbeda nyata terhadap persen hidup dan pertumbuhan tanaman, tetapi perlakuan jenis telah memberikan pengaruh yang nyata terhadap persen hidup. Persen hidup $S$. leprosula lebih tinggi dibandingkan dengan $S$. johorensis masing-masing sebesar $81,11 \%$ dan $57,24 \%$. Untuk perlakuan interaksi antara $S$. leprosula yang berasal dari stek telah memberikan pengaruh yang nyata terhadap riap tinggi,
\end{abstract}


sebesar $86,28 \mathrm{~cm}$ dibanding dengan interaksi lainnya. Dengan demikian jenis $S$. leprosula dari stek dapat digunakan untuk ditanam dalam program rehabilitasi hutan alam.

\section{Kata kunci : Meranti merah, benih dan stek, tablet mikoriza, Shorea johorensis Foxw., Shorea leprosula Miq.}

\section{PENDAHULUAN}

Laju kerusakan hutan pada saat ini semakin meningkat diakibatkan oleh penebangan ilegal, kebakaran hutan dan perladangan, sehingga perlu segera dilakukan kegiatan reboisasi lahan hutan. Untuk kegiatan reboisasi lahan hutan tentunya diperlukan bibit dalam kuantitas dan kualitas yang baik. Pada saat ini kegagalan rehabilitasi lahan hutan dikarenakan oleh ketersediaan bibit belum memenuhi mutu standar, ditambah dengan kondisi fisik lahan, khususnya di Kalimantan Timur. Lahan yang akan direhabilitasi pada umumnya memiliki pH yang rendah, lapisan top-soil tipis dan miskin unsur hara terutama fosfor $(\mathrm{P})$. Dari ketiga hal tersebut yang menyebabkan kegagalan, sehingga banyak tanaman di lapangan mengalami stres (transplant shock) yang mengakibatkan kematian bibit setelah ditanam.

Untuk mengatasi rendahnya kualitas bibit terutama dari jenis dipterokarpa di persemaian, maka perlu diupayakan penggunaan mikoriza sebagai pupuk hayati. Cendawan mikoriza dengan akar tanaman inangnya dalam siklus hidupnya akan membentuk proses simbiosis yang bersifat obligat. Keuntungan dari adanya siombiosis tersebut, yaitu dapat meningkatkan penyerapan air dan unsur hara terutama fosfor ke tanaman inang, begitu pula cendawan mikoriza juga mendapat karbohidrat hasil fotosintesis dari tanaman. Keuntungan lain dengan adanya cendawan mikoriza dapat meningkatkan ketahanan akar tanaman terhadap serangan patogen dan kekeringan (Mark and Foster, 1973; Malajczuk et al., 1994) dan dapat memproduksi hormon tumbuh IAA (Gay dan Debaud, 1987), serta memperbaiki struktur tanah (De la Cruz, 1982). Oleh karena itu cendawan mikoriza mempunyai peranan penting dalam meningkatkan kualitas pertumbuhan, khususnya pada tanaman jenis dipterokarpa.

Asosiasi antara cendawan mikoriza dengan akar tanaman (inang) dapat terbentuk setelah terjadi proses infeksi cendawan mikoriza ke dalam akar tanaman baik yang diawali oleh berkecambahnya spora maupun infeksi oleh bagian vegetatif dari cendawan mikoriza (Supriyanto et al., 2003). Proses penularan tersebut dapat terjadi baik secara alami maupun dengan bantuan manusia. Namun demikian, bahan generatif dalam bentuk spora ketersediannya sangat dipengaruhi oleh berbagai faktor lingkungan sehingga tidak tersedia setiap saat. Oleh karena itu, pengemasan inokulum berupa tablet merupakan salah satu alternatif untuk mengatasi kendala pengadaan inokulum tersebut. Inokulasi cendawan mikoriza dapat dilakukan dengan berbagai cara, di antaranya dengan tablet mikoriza atau kapsul mikoriza, spora, miselium dan alganite (Supriyanto, 1996).

Perlu diketahui bahwa penyedian bibit dari jenis Dipterocarpaceae tidak mudah dilakukan dengan cara generatif, karena masa berbunga dan berbuah massal (panen raya) tidak terjadi sepanjang tahun dan benih tidak dapat disimpan lama. Tetapi jenis ini dapat dibiakkan secara vegetatif melalui stek pucuk dengan sangat mudah terutama untuk jenis $S$. johorensis dan $S$. leprosula baik pada media padat maupun cair (Priadjati dan Tolkamp, 2001). Dipilihnya kedua jenis Dipterocarpaceae dalam penelitian ini, yakni $S$. johorensis dan S. leprosula karena merupakan jenis unggulan dalam program Tebang Pilih Tanam Indonesia Intensif (TPTII) sebagai jenis yang mempunyai pertumbuhan yang cepat. 
Tujuan penelitian ini adalah untuk mengetahui riap dan dosis tablet mikoriza yang efektif terhadap kedua jenis meranti merah dari bibit yang berasal dari benih dan stek. Diharapkan hasil penelitian ini dapat memberikan informasi terhadap penanaman jenis meranti merah dalam rangka menunjang program rehabilitasi hutan alam.

\section{BAHAN DAN METODE PENELITIAN}

\section{A. Lokasi dan Waktu}

Pembuatan petak coba aplikasi tablet ektomikoriza pada jenis $S$. johorensis dan $S$. leprosula dari bibit yang berasal dari benih dan stek telah dilakukan pada areal hutan belukar di areal Izin Usaha Pemanfaatan Hasil Hutan Kayu (IUPHHK) PT ITCIKU, Kenangan Balikpapan. Lokasi tersebut secara adminitratif termasuk Desa Kenangan, Kecamatan Penajam, Kabupaten Penajam Paser Utara, Provinsi Kalimantan Timur. Penelitian dilakukan pada pertengahan tahun 2005 dan dimulai dengan penyemaian benih dan proses perakaran bibit stek jenis $S$. johorensis dan $S$. leprosula. Setelah empat bulan bibit dari benih dan stek diinokulasi dengan tablet mikoriza di persemaian, kemudian penanaman dilakukan pada bulan Febuari 2006 dan diamati bulan Pebuari 2007.

\section{B. Tanah dan Iklim}

Jenis tanah di lokasi penelitian termasuk Podsolik Merah Kuning pada umumnya memiliki pH yang rendah, lapisan top-soil tipis dan miskin unsur hara terutama fosfor $(\mathrm{P})$. Berdasarkan klasifikasi iklim Schmidt dan Fergusson (1951) termasuk tipe iklim A dengan rata-rata curah hujan tahunan berkisar antara $1.682-2.314 \mathrm{~mm}$ dan hari hujan $72-154$ hari. Ketinggian tempatnya antara $40 \mathrm{~m}-150 \mathrm{~m}$ dari permukaan laut.

\section{Bahan}

Bahan yang digunakan adalah bibit yang berasal dari benih dan stek kedua jenis meranti merah (S. johorensis dan S. leprosula). Benih diambil dari pohon plus PT ITCIKU pada waktu panen raya bulan Maret 2005, kemudian di kecambahkan di persemaian PT ITCIKU. Untuk bibit yang berasal dari stek diambil dari kebun pangkas yang telah berumur dua tahun, kemudian dilakukan proses perakaran pada media padat (pasir) di PT ITCIKU. Setelah dua minggu bibit-bibit tersebut disapih dalam kantong plastik berisi tanah yang telah disterilkan, kemudian dilakukan inokulasi dengan spora cendawan Scleroderma columnare yang dikemas dalam bentuk tablet.

Tablet mikoriza dibuat dari tanah yang telah disterilkan kemudian diayak halus, dicampur dengan spora $S$. columnare dan pupuk anorganik $\left(\mathrm{P}_{2} \mathrm{O}_{5}\right)$ dengan perbandingan berat 50 :1: 1 . Selanjutnya diaduk merata dan diberi air secukupnya agar mudah dicetak. Setelah tablet tersebut terbentuk dikering anginkan, kemudian dimasukkan ke dalam kantong plastik dan disimpan pada suhu kamar yang dilengkapi dengan air condition $(\mathrm{AC})$ pada suhu $20^{\circ} \mathrm{C}$. Berat tablet antara 0.67 gr 0.72 gr dengan jumlah spora sebanyak $10.000-16.000$ spora per tablet dan pembuatan tablet mikoriza tersebut dilakukan di Laboratorium Mikoriza Balai Penelitian Teknologi Perbenihan, Samboja Kalimantan Timur. Berdasarkan hasil pengamatan tablet ini dapat disimpan maksimal selama 3 bulan pada suhu $4^{\circ} \mathrm{C}$ di kulkas atau $20^{\circ} \mathrm{C}$ suhu kamar (Omon, 2006). Sebelum dilakukan penanaman contoh akar masing-masing diambil sebanyak 5 bibit pada setiap perlakuan dari kedua jenis tersebut, kemudian dihitung akar yang terinfeksi mikoriza di laboratorium. Perhitungan akar yang bermikoriza di hitung dengan menggunakan alat mikroskop terhadap akar yang terinfeksi dan tidak terinfeksi cendawan 
mikoriza. Untuk penyulaman dilakukan setelah bibit berumur tiga bulan ditanam dan pemeliharaan setiap tiga bulan sekali atau empat kali dalam setahun.

\section{Rancangan Percobaan}

Petak coba dibuat berukuran $75 \mathrm{~m}$ x $45 \mathrm{~m}$ dengan jarak tanam $6 \mathrm{~m} \times 3 \mathrm{~m}$. Rancangan percobaan yang dilakukan adalah faktorial $2 \times 2 \times 3$ dengan pola acak lengkap terdiri tiga faktor, yaitu

Faktor A adalah jenis terdiri dari :

$\mathrm{A} 1=S$. johorensis dan

$\mathrm{A} 2=$ S. leprosula .

Faktor B adalah asal bibit, yaitu:

$\mathrm{B} 1=$ bibit dari biji dan

$\mathrm{B} 2=$ bibit berasal dari stek.

Faktor $\mathrm{C}$, adalah bibit yang dinokulasi dengan tablet mikoriza, yaitu

$\mathrm{C} 0=$ tidak dinokulasi

$\mathrm{C} 1=$ diinokulasi dengan satu tablet,

$\mathrm{C} 2=$ diinokulasi dengan dua tablet

Setiap satuan perlakuan dari bibit yang berasal dari benih dan stek kedua jenis meranti merah tersebut ditanam masing-masing sebanyak 15 bibit dengan ulangan sebanyak tiga kali. Jadi jumlah bibit yang diamati sebanyak $2 \times 2 \times 3 \times 15 \times 3=540$ bibit.

\section{E. Analisis Data}

Parameter yang diukur adalah persen hidup dan pertambuhan tinggi (riap tinggi) di lapangan. Analisis data yang digunakan adalah analisis variance (ANOVA). Apabila ada perbedaan signifikan antar perlakuan akan dilanjutkan dengan uji lanjutan Tukey (Haeruman, 1975).

\section{HASIL DAN PEMBAHASAN}

\section{A. Persentase kolonisasi akar bermikoriza}

Hasil analisis akar terhadap persen kolonisasi akar bermikoriza pada kedua jenis bibit yang berasal dari benih maupun stek, seperti disajikan pada Tabel 1 .

Tabel (Table) 1. Rata-rata persen kolonisasi akar bermikoriza pada bibit $S$. johorensis dan $S$ leprosula dari benih dan stek empat bulan setelah diinokulasi di persemaian (Average of mycorrhized root colonization percentage of $\mathrm{S}$. johorensis and $\mathrm{S}$. leprosula from seeds and cuttings four months after inoculation in nursery)

\begin{tabular}{|l|l|c|c|c|}
\hline \multicolumn{1}{|c|}{ Jenis (Species) } & bibit (Seedling) & \multicolumn{3}{|c|}{ Dosis tablet (Tablet dosage) } \\
\hline \hline & & $\begin{array}{c}\text { Kontrol } \\
\text { (Control) }\end{array}$ & $\begin{array}{c}\text { Satu tablet } \\
\text { (one tablet) }\end{array}$ & $\begin{array}{c}\text { Dua tablet } \\
\text { (Two tablets) }\end{array}$ \\
\hline S. johorensis & Benih(seed) & 53 & 62 & 64 \\
\hline & Stek (cutting) & 50 & 52 & 60 \\
\hline S. leprosula & Benih (seed) & 48 & 51 & 60 \\
\hline & Stek (cutting) & 49 & 50 & 63 \\
\hline
\end{tabular}


Tabel 1 memperlihatkan bibit yang berasal dari benih dan stek pada kedua jenis $(S$. johorensis dan $S$. leprosula) yang tidak diinokulasi menunjukkan rata-rata hampir $50 \%$ akarnya terkolonisasi cendawan mikoriza. Tetapinya persentase kolonisasi akar bermikoriza yang diinokulasi masih lebih besar dibandingkan dengan tidak diinokulasi, walaupun secara analisis statistik tidak menunjukkan perbedaan yang nyata.

Bibit yang tidak diinokulasi dengan tablet mikoriza persentase kolonisasi akar bermikoriza berkisar antara 48\% - 53\% (Tabel 1). Terjadinya kolonisasi akar bermikoriza tersebut adalah berasal dari jamur liar yang berasal dari air dan udara dan keberadaan jamur tersebut tidak mematikan bibit seperti yang dilaporkan terhadap stek $S$. leprosula di rumah kaca (Omon, 2002). Hal yang sama terjadi seperti dilaporkan oleh Omon (2002) dan Omon (2006) persentase kolonisasi akar yang terjadi pada stek S. leprosula dan S. johorensis pada perlakuan tidak diinokulasi (kontrol) masing-masing sebesar $21 \%$ dan $58 \%$ di rumah kaca. Oldeman (2001) mengemukakan bahwa jamur tersebut termasuk dalam kelompok "early stage", yaitu Thelophora sp., Inocybe sp. dan Hebeloma sp. yang biasa terdapat di rumah kaca dan dipersemaian, termasuk juga ke dalam kelompok cendawan mikoriza pionir.

\section{B. Persentase Hidup}

Hasil analisis keragaman (Lampiran 1) menunjukkan bahwa dosis tablet mikoriza, macam bibit, semua interaksi antar perlakuan belum menunjukkan perbedaan yang nyata terhadap persen hidup setelah satu tahun ditanam di lapangan. Tetapi perlakuan jenis telah memberikan perbedaan yang sangat nyata terhadap persen hidup pada kedua jenis Shorea.

Dari hasil uji lanjutan Tukey pada taraf W $(0,05)$ sebesar 6,78 menunjukkan bahwa untuk persen hidup jenis $S$. leprosula lebih tinggi dibandingkan dengan $S$. johorensis, yaitu masing-masing sebesar $81,11 \%$ dan $57,24 \%$. Rata-rata persentase hidup bibit yang berasal dari benih maupun stek ditanam di lapangan pada umur satu tahun masih cukup tinggi, yaitu masing-masing sebesar $65,89 \%$ untuk bibit yang berasal dari benih sebesar $72,46 \%$ bibit yang berasal dari stek. Akan tetapi antar jenis terjadi perbedaan yang nyata, yaitu untuk jenis $S$. leprosula persentase hidup dan pertumbuhan tinggi lebih besar dibandingkan dengan $S$. johorensis. Perbedaan ini disebabkan oleh faktor genetik, lingkungan dimana jenis tersebut tumbuh dan kesesuaian atau asosiasi jamur terhadap jenis tersebut. Seperti dikemukakan oleh Ardikusuma dan Noerkamal (1955) untuk pertumbuhan jenis $S$. leprosula membutuhkan paling sedikit 30 hari hujan dan 4 bulan dalam musim kemarau. Selain itu jenis ini dapat tumbuh di tempat yang tidak beroksigen $\left(\mathrm{O}_{2}\right)$ selama lebih kurang 75 hari. Hal ini sesuai dengan kondisi pada waktu itu bibit ditanam, yaitu pada waktu penanaman bulan Pebruari 2006 telah turun hujan lebih kurang satu bulan dan bulan berikutnya terjadi musim kemarau berkepanjangan sampai lebih dari empat bulan. Berdasarkan hal tersebut di atas tampak bahwa persen hidup jenis $S$. leprosula masih cukup tinggi yaitu sebesar $81,1 \%$.

\section{Pertumbuhan tinggi}

Perlakuan dosis tablet mikoriza, asal bibit dan semua interaksi tidak menunjukkan perbedaan pengaruh yang nyata terhadap pertumbuhan atau riap tinggi tanaman kedua jenis. Kecuali untuk perlakuan jenis dan interaksi antara jenis dengan asal bibit menunjukkan perbedaan yang nyata terhadap riap tinggi (Lampiran 2).

Dari hasil uji lanjutanTukey pada taraf W $(0,05)$ sebesar10,42 untuk interaksi antara jenis dengan asal bibit menunjukan adanya perbedaan yang nyata terhadap riap tinggi. Hasil uji lanjutan Tukey disajikan pada Tabel 2. 
Tabel (Table) 2. Hasil uji lanjutan Tukey terhadap pertambuhan tinggi (riap tinggi) setelah satu tahun ditanam di lapangan. (Results of Tukey signifiicant different test for height growth after one year in the field

\begin{tabular}{|c|c|}
\hline $\begin{array}{c}\text { Kombinasi perlakuan } \\
\text { (treatment combination) }\end{array}$ & Riap tinggi (Heigh growth) \\
\hline $\mathrm{A}_{1} \mathrm{~B}_{2}$ & $41,97 \mathrm{a}$ \\
$\mathrm{A}_{1} \mathrm{~B}_{1}$ & $74,48 \mathrm{~b}$ \\
$\mathrm{~A}_{2} \mathrm{~B}_{1}$ & $85,44 \mathrm{c}$ \\
$\mathrm{A}_{2} \mathrm{~B}_{2}$ & $86,28 \mathrm{c}$ \\
\hline
\end{tabular}

Keterangan (Remark): Nilai rata-rata yang diikuti oleh huruf yang sama tidak berbeda nyata (Values followed by the same letters are not significantly different).

Pada Tabel 2 terlihat kombinasi perlakuan antara jenis $S$. leprosula dengan bibit yang berasal dari stek menunjukkan perbedaan yang nyata dibandingkan dengan kombinasi lainnya. Walaupun belum tampak pengaruh pemberian inokulasi tablet mikoriza pada kedua jenis, tetapi terlihat ada kecendurungan dengan tinggi dosis tablet mikoriza dapat meningkatkan persen kolonisasi akar bermikoriza di persemaian. Selain itu persentase kolonisasi akar bermikoriza berbeda pada setiap jenis. Hal ini dikarenakan besar kecilnya persentase kolonisasi akar bermikoriza ditentukan juga oleh kesesuaian jenis cendawan mikoriza untuk berasosiasi dengan inangnya (Omon, 1994; Smits, 1994; Smith dan Read, 1997). Seperti yang dilaporkan oleh Harley dan Smith (1983) pada tanaman Betula pedula dan $B$. pubescens yang menghasilkan variasi persentase kolonisasi akar bermikoriza yang berbeda.

Sehubungan belum adanya pengaruh inokulasi tablet mikoriza terhadap pertumbuhan tanaman muda pada kedua jenis meranti merah, mungkin dikarenakan inokulum spora yang dikemas dalam bentuk tablet hanya satu jenis cendawan (single species), yaitu $S$. columnare, sehingga belum berperan optimal terhadap pertumbuhan kedua jenis tanaman muda meranti merah. Seperti yang dilaporkan oleh Supriyanto dkk., (2003) bahwa jenis cendawan $S$. columnare ini termasuk jenis pionir dan hanya berperan efektif pada tingkat semai di persemaian.

Berdasarkan hasil penelitian menunjukkan bahwa penggunaan spora campuran dari beberapa jenis cendawan ektomikoriza atau coktail mikoriza dari jenis Amanita sp, Russulla sp dan $S$. columare menghasilkan pertumbuhan stek $S$. leprosula yang lebih baik dibandingkan dengan spora dari satu jenis cendawan. Amanita sp dan Russulla sp dikenal sebagai cendawan "late stage" yang akan berperan optimal pada kondisi vegetasi hutan yang telah mantap (Supriyanto dkk., 2003). Dengan demikian untuk penaman jenis dipterokarpa sebaiknya menggunakan inokulasi dari inokolum campuran spora dari beberapa jenis cendawan mikoriza atau coktail dibandingkan dengan satu jenis cendawan. Asossiasi cendawan yang terbentuk dari inokolum campuran diharapkan dapat memberi peran efektif baik dari tingkat bibit maupun setelah penanaman di lapangan.

\section{KESIMPULAN DAN SARAN}

\section{A. Kesimpulan}

1. Inokolusasi dengan tablet mikoriza belum memberikan persen hidup dan riap tinggi yang efektif. Persen hidup dan riap tinggi Shorea leprosula Miq. lebih besar dibandingkan dengan Shorea johorensis Foxw., yaitu masing-masing sebesar $81,1 \%$ dan $57,3 \mathrm{~cm}$. 
2. Shorea leprosula Miq. yang berasal dari stek memberikan pertumbuhan lebih baik terhadap riap tinggi, yaitu sebesar $86,3 \mathrm{~cm}$.

3. Belum efektifnya pemberian inokulum tablet mikoriza terhadap pertumbuhan kedua jenis Shorea, dikarenakan tablet yang dikemas hanya terdiri dari satu jenis cendawan mikoriza (single species).

\section{B. Saran}

Untuk pengujian dan efektivitas sebaiknya menggunakan jenis cendawan mikoriza tunggal (single species), tetapi untuk aplikasi di lapangan sebaiknya menggunakan jenis cendawan mikoriza campuran (cocktail) mengingat setiap cendawan mikoriza memiliki peran spesifik.

\section{DAFTAR PUSTAKA}

Ardikoesuma, R.I. dan Noerkamal 1955. Percobaan tanaman Shorea leprosula Miq. di Jawa. Rimba Indonesia 4: 299-333.

De la Cruz, R.E. 1982. Mycorrhizae in forestry. In : Training Course on Biological Aspect of Silviculture, BIOTROP, Bogor. Tidak dipublikasikan.

Gay, J.C. and J.C. Debaud. 1987. Genetic study on indole-3-acetic acid production by ectomycorrhizae Hebeloma species inter and intra specific variability in homo and dikaryotic mycelia. Appl. Microba Biotechnol 26: 141-146.

Haeruman, H., 1975. Prosedure analisa rancangan percobaan. bagian pertama. Bagian Perentjanaan Hutan. Departemen Mangemen Hutan, Fakultas Kehutanan, IPB, Bogor. $78 \mathrm{~h}$.

Harley, J.L. and S.E. Smith., 1983. Mycorrhizal symbiosis. Academic Press, London-New York.

Malajczuk, N.P., P. Reddell and M. Brundrett. 1994. Role of mycorrhizae fungi in mine site reclamation. In : F.L. Pfleger and R. G. Linderman (eds). Mycorrhizae and Plant Health. 83-100.

Marks G.C. and R.C. Foster. 1973. Structure, morphogenesis and ultrastructure of ectomycorrhizae. In : Marks, G.C. and T.T. Kozlowski (eds). Ectomycorrhizae their ecology and physiology. Academic Press Inc. New York. 2-41.

Oldeman, R.A.A., 2001. Diagnosis of complex ecosystems. CD Rom Dice 5.1. Easy Acess Software, Wageningen, the Netherlands

Omon, R.M.1994. Pengaruh jenis cendawan mikoriza dan media pertumbuhan terhadap perkembangan stek Shorea leprosula Miq. Pasca Sarjana IPB, Bogor. (tidak diterbitkan).

Omon, R. M. 2002. Dipterocarpaceae: Shorea leprosula Miq., cuttings, mycorrhizae and nutrients. Tropenbos Series No 7. The Tropenbos Foundation, Wageningen, the Netherlands. 144 pp.

Omon, R.M. 2006. Pengaruh suhu dan lama penyimpanan tablet mikoriza terhadap pertumbuhan stek Shorea johorensis Foxw. di rumah kaca. Jurnal Peneltian Hutan dan Konservasi Alam Vol. III, No 1: 83-93. Badan Penelitian dan Pengembangan Kehutanan, Puslitbang Hutan dan Konservasi Alam Bogor.

Pridjati, A. dan G.W. Tolkamp., 2002. Manual persemaian Dipterocarpaceae. Badan Penelitian dan Pengembangan Kehutanan, Tropenbos International, SFMP (GTZ), APHI, IFSP (DANIDA). h. IV-1 IV-7

Schmidt dan Ferguson, 1951. Rainfall types based on dry and wet period ratios for Indonesia with Western New Guinea. Verhandelingen No. 42. Jawatan Meteorologi dan Geofisika, Jakarta. 
Smits, W.T.M. 1994. Dipterocarpaceae: Mycorrhizae and regeneration. Tropenbos Series No 9. The Tropenbos Foundation, Wageningen, the Netherlands.

Smith, E.S. dan D.J. Read. 1997. Mycorrhizal symbiosis. Academic Prees, London UK.

Supriyanto, 1996. Penggunaan inokulum alganit dalam uji efektivitas pada semai beberapa jenis Dipterocarps. Laporan Penelitian 1995/1996. Direktorat Pendidikan Tinggi Proyek Pengembangan Biotrop, Bogor. Tidak dipublikasikan

Supriyanto, U.S. Irawan dan I.W.S. Dharmawan. 2003. Teknik pengemasan inokulum cendawan mikoriza. Paper dalam Seminar Tahunan Asosiasi Mikoriza Indonesia, Bandung 16 September 2003. 
Lampiran (Appendix) 1. Sidik ragam pengaruh dosis tablet mikoriza, jenis meranti dan asal dari benih dan stek terhadap persen hidup setelah satu tahun di lapangan (Analysis of variance the effect of tablet mycorrhizal dosag, species and seedling from seeds and cuttings to survival percentage after one year in the field)

\begin{tabular}{||l|r|r|r|r|r||}
\hline $\begin{array}{l}\text { Sumber keragaman } \\
\text { (Sources of variance) }\end{array}$ & $\begin{array}{l}\text { Db } \\
(D f)\end{array}$ & \multicolumn{1}{c|}{$\begin{array}{c}\text { JK } \\
(S S)\end{array}$} & \multicolumn{1}{c|}{$\begin{array}{c}\text { KT } \\
(M S)\end{array}$} & $\begin{array}{c}\text { F.Hit } \\
\text { (F.Calc) }\end{array}$ & $\begin{array}{c}\text { F.Tabel } \\
\text { (F.Table) }\end{array}$ \\
\hline \hline Perlakuan (treatment) & & & & & \\
\hline $\mathrm{A}=$ jenis (Species) & 1 & 5129,98 & 5129,98 & $26,44 * *$ & 4.26 \\
\hline $\mathrm{B}=$ Bibit (Seedling) & 1 & 389,27 & 389,27 & $2,01 \mathrm{~ns}$ & 4,26 \\
\hline $\mathrm{C}=$ Dosis (dosage) & 2 & 109,36 & 218,72 & $0,56 \mathrm{~ns}$ & 3,40 \\
\hline Interaksi AB (Interaction AB) & 1 & 325,73 & 325,73 & $1,68 \mathrm{~ns}$ & 4,26 \\
\hline Interaksi AC (Intera ction AC) & 2 & 887,94 & 443,97 & $2,29 \mathrm{~ns}$ & 3,40 \\
\hline Interaksi BC (Interaction BC) & 2 & 1,06 & 0,53 & $0,00 \mathrm{~ns}$ & 3,40 \\
\hline Inteaksi ABC (Interaction ABC) & 2 & 331,75 & 165,87 & $0,85 \mathrm{~ns}$ & 3,40 \\
\hline Galat (Error) & 24 & 4656,71 & 194,03 & & \\
\hline Jumlah (Total) & 35 & 11941,16 & & & \\
\hline
\end{tabular}

Keterangan: $\mathrm{ns}=$ tidak berbeda nyata (No significant different) ** = Berbeda sangat nyata (Highly significant different)

Lampiran (Appendix) 2. Sidik ragam pertumbuhan meranti merah berasal dari benih dan stek terhadap pertumbuhan tinggi setelah satu tahun di lapangan (Analysis of variance the growth of red meranti from seeds and cuttings to height growth after one year in the field)

\begin{tabular}{||l|r|r|r|r|r||}
\hline $\begin{array}{l}\text { Sumber keragaman } \\
\text { (Sources of variance) }\end{array}$ & \multicolumn{1}{c|}{$\begin{array}{c}\mathrm{Db} \\
(\mathrm{Df})\end{array}$} & \multicolumn{1}{c|}{$\begin{array}{c}\mathrm{JK} \\
(\mathrm{SS})\end{array}$} & \multicolumn{1}{c|}{$\begin{array}{c}\mathrm{KT} \\
(\mathrm{MS})\end{array}$} & $\begin{array}{c}\text { F.Hit } \\
\text { (F.Calc) }\end{array}$ & $\begin{array}{c}\text { F.Tabel } \\
\text { (F.Table) }\end{array}$ \\
\hline Perlakuan (treatment) & & & & & \\
\hline $\mathrm{A}=$ jenis (Species) & 1 & 3054,15 & 3054,15 & $11,89^{* *}$ & 4.26 \\
\hline $\mathrm{B}=$ Bibit (Seedling) & 1 & 1002,81 & 1002,81 & $3,91 \mathrm{~ns}$ & 4,26 \\
\hline $\mathrm{C}=$ Do sis (dosage) & 2 & 629,36 & 314,68 & $1,23 \mathrm{~ns}$ & 3,40 \\
\hline Interaksi AB (Interaction AB) & 1 & 1112,16 & 1112,16 & $4,33^{*}$ & 4,26 \\
\hline Interaksi AC (Interaction AC) & 2 & 10,68 & 5,34 & $0,02 \mathrm{~ns}$ & 3,40 \\
\hline Interaksi BC (Interaction BC) & 2 & 65,05 & 32,53 & $0,13 \mathrm{~ns}$ & 3,40 \\
\hline Inteaksi ABC (Interaction ABC) & 2 & 159,06 & 79,53 & $0,31 \mathrm{~ns}$ & 3,40 \\
\hline Galat (Error) & 24 & 6162,74 & 12196,00 & & \\
\hline \hline Jumlah (Total) & 35 & 11941,16 & & & \\
\hline
\end{tabular}

Keterangan (remarks): $\mathrm{ns}=$ tidak berbeda nyata (No significant different)

** = Berbeda sangat nyata (Highly significant different)

* = Berbeda nyata (Significant different) 